\title{
Costs and repeat rates associated with colonoscopy observed in medical claims for commercial and Medicare populations
}

\author{
Bruce Pyenson", Charles Scammell and Jonah Broulette
}

\begin{abstract}
Background: Colorectal cancer is among the leading causes of cancer and cancer-related mortality in the United States. The incidence and mortality associated with CRC can be reduced with preventive screening. Inadequate bowel preparation has been associated with missed adenomas and the need for repeat colonoscopies.

Methods: Separate claims source databases were analyzed to determine the costs associated with colonoscopy in the commercial and Medicare populations. Observed repeat rates for colonoscopy within 4 years of initial screening were also examined.

Results: Among the 6 most commonly used billing codes, the average allowed cost for an episode of colonoscopy in 2010 was $\$ 2,146$ in the commercial population and $\$ 1,071$ in the Medicare population, with average cost sharing of $\$ 334$ and $\$ 275$, respectively. The portion of colonoscopies associated with a biopsy or polyp removal exceeded $50 \%$ in the commercial and Medicare populations. Approximately 57\% of colonoscopies in the commercial population were associated with claims for a prescription bowel preparation product within 30 days prior to the procedure. Three branded and three generic bowel cleansing products accounted for approximately $75 \%$ of the total number of prescription claims for colonoscopy. Given literature reports that up to $25 \%$ of patients receive inadequate bowel preparation, the rate of repeat colonoscopy within 4 years of initial screening was lower than expected among patients who were not coded with common clinical reasons for early repeat: benign neoplasm, lesion, or polyp removed at initial screening colonoscopy.

Conclusions: The reported rates of inadequate bowel preparation are $15 \%$ to $25 \%$, but the rates of repeat colonoscopy found in our analysis are much lower; this is a risk concern considering the reported, significant miss rate of adenomas secondary to inadequate bowel preparation.
\end{abstract}

Keywords: Colonoscopy, Bowel preparation, Actuarial analysis, Colorectal cancer screening, Claims data

\section{Background}

Colorectal cancer (CRC) is the fourth leading cause of cancer and the second leading cause of cancer deaths after lung cancer in the United States [1]. The lifetime risk of developing CRC is approximately 1 in 20 for both males and females [1]. CRC develops slowly over a period of several years [2], allowing an opportunity for screening and prevention.

CRC is one of the most preventable cancers, which helps explain why CRC screening has become a public health priority in recent years. Several groups, including

\footnotetext{
* Correspondence: bruce.pyenson@milliman.com

Milliman, Inc., One Pennsylvania Plaza, 38th floor, New York, NY 10119, USA
}

the US Multi-Society Task Force on CRC, American College of Gastroenterology, US Preventive Services Task Force, and National Comprehensive Cancer Network, have published recommendations for CRC screening [3-6]. A patient's screening strategy will depend on the individual's risk, age, family history of CRC, and incidence of other serious gastrointestinal conditions. However, starting at 50 years of age, an individual of average risk for CRC should begin regular screening for CRC. Screening may include annual fecal occult blood tests or fecal immunochemical tests (with colonoscopy reserved for patients testing positive for $\mathrm{CRC}$ ) or endoscopic procedures performed every 5 years for flexible

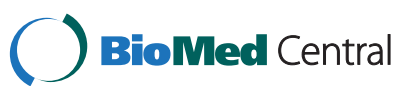


sigmoidoscopy or every 10 years for colonoscopy. In some patients, more frequent screening or the use of a stool DNA test or computed tomography colonoscopy may be appropriate.

Screening of any type considerably reduces the mortality associated with the disease [7]. In average-risk patients, screening with colonoscopy has been demonstrated to decrease the incidence of CRC by $67 \%$ and CRC deaths by $65 \%$ [8]. Furthermore, colonoscopic screening and removal of adenomatous polyps reduced the mortality from CRC by $53 \%$ relative to the incidence-based mortality from CRC in the general population [9].

Screening for CRC remains underused compared with breast and cervical cancer screening. Data from the 2010 National Health Interview survey indicated that compliance with recommended screening for breast and cervical cancer exceeded $72 \%$ [10]. However, among adults 50 years and older $58.6 \%$ are current with recommended CRC screening according to data from the recent National Health Interview or $65.4 \%$ according to the telephonic Behavioral Risk Factor Surveillance surveys [10]. These estimates are below the $75 \%$ goal set by the American Cancer Society and the $70.5 \%$ goal set by the Department of Health and Human Services for adults $\geq 50$ years [11,12].

Colonoscopy provides a visual diagnosis of inflamed tissues, abnormal growths, ulcers, and bleeding from the rectum and colon to the small intestine. It allows for both diagnostic assessment of the colon and certain therapeutic interventions (removal of polyps) during the same procedure. Poor bowel preparation deters procedural success and may lead to missed polyps and cancer [13], prolonged procedural time to clean the colon, and cancelled procedures [14]. Rates of poor preparation are commonly reported between about 15\% and 25\% [15-17], and can lead to a recommendation for repeat colonoscopy.

The objectives of this manuscript are to 1) analyze the average cost and cost sharing associated with screening colonoscopy, including the cost of products for bowel preparation, among the most commonly reported procedure codes in the commercial and Medicare populations, and 2) determine the repeat rate of colonoscopy in patients without evidence of high risk for CRC in the commercial and Medicare populations. We report the repeat rate separately for patients depending on whether the initial colonoscopy procedure included a biopsy or removal of polyp. We refer to the repeat rate for patients with an initial colonoscopy procedure not including a biopsy or removal of polyp as the "more restrictive" repeat rate. The repeat rate for all selected patients is referred to as the "less restrictive" repeat rate.

\section{Methods}

Two claims source databases were used in this analysis; the commercial population data was derived from
Truven MarketScan ${ }^{\circ}$ and the Medicare population data was gathered from the Medicare 5\% beneficiary sample. MarketScan includes inpatient, outpatient, and drug claims for individuals covered by benefit plans of large employers, health insurers, and government employers. Insured groups with high deductible health plans or capitation, and individuals $>65$ years or not associated with an active employee were excluded from the commercial population analysis. The Medicare 5\% beneficiary sample is a limited data set that contains all Medicare Part A and Part B paid claims generated by a sample of Medicare beneficiaries. Exclusions in the Medicare population analysis included beneficiaries who were disabled, institutionalized, eligible for Medicaid, or enrolled in a health maintenance organization.

\section{Screening colonoscopy}

To determine the cost of screening colonoscopy in the commercial and Medicare populations, colonoscopies performed in 2010 with a selected Healthcare Common Procedure Coding System (HCPCS) code were selected after exclusions for patients identified as having pre-exisitng high risk conditions based on International Classification of Disease (ICD-9) diagnosis codes. International Classification of Disease (ICD-9) diagnosis codes were analyzed (Table 1). All costs on the day of colonoscopy for outpatients were included. All facility costs for inpatients were excluded.

The average allowed and paid costs and patient cost sharing were analyzed in both populations. Claims for bowel preparation prescriptions, percentage of colonoscopies with prescriptions filled within 30 days prior to the date of screening colonoscopy, and the average cost of bowel preparation were evaluated in the commercial population.

The allowed amount for a service is a dollar amount typically considered payment-in-full for a member insured by an insurance company and its associated network of healthcare providers. The allowed amount is typically a discounted rate rather than the provider's actual charge. The insurer directly pays the healthcare provider the paid amount. The patient bears responsibility for cost sharing, which may include copays, coinsurances, and deductibles.

\section{Repeat screening colonoscopy}

To examine the repeat rate of screening colonoscopy in the commercial and Medicare populations, colonoscopies performed in 2005 with a repeat colonoscopy within 4 years (48 months in commercial population; 16 quarters in Medicare population) with an eligible HCPCS code and an eligible ICD-9 diagnosis code (Table 1) were analyzed. Colonoscopies beyond the first repeat screening were ignored. Patients without continuous enrollment throughout the study period were 
Table 1 Eligible codes to identify screening colonoscopies of interest

\begin{tabular}{|c|c|}
\hline Code & Definition \\
\hline \multicolumn{2}{|c|}{ Healthcare Common Practice Coding System (HCPCS) } \\
\hline 45378 & Diagnostic/screening colonoscopy for non-Medicare patients \\
\hline 45380 & Colonoscopy with biopsy single/multiple \\
\hline 45383 & $\begin{array}{l}\text { Colonoscopy with ablation of tumors, polyps, or other lesions not } \\
\text { amenable to removal by hot biopsy forceps }\end{array}$ \\
\hline 45384 & Removal of polyps or other lesions by hot biopsy \\
\hline 45385 & Removal of polyps or other lesions by snare technique \\
\hline G0121 & Screening colonoscopy for other Medicare patients \\
\hline \multicolumn{2}{|c|}{ International Classification of Disease (ICD-9) Diagnosis for excluding patients with pre-existing high-risk conditions } \\
\hline V76.51 & Special screening for malignant neoplasm, colon \\
\hline 211.3 & Benign neoplasm of other parts of digestive system, colon \\
\hline
\end{tabular}

excluded. Some of the HCPCS codes could indicate a condition that would justify a follow-up before the usual 10 year period; these were colonoscopies whose code indicated a biopsy or removal of a benign neoplasm, lesion, or polyp occurred during the initial screening colonoscopy (HCPCS codes: 45378 and G0121; ICD-9 code: V76.51). The repeat rate for colonoscopy patients whose initial colonoscopy did not include one of these biopsy or polyp removal procedures was tabulated separately, which is characterized as the more restrictive repeat rate. The less restrictive repeat rate calculation includes all patients with an initial colonoscopy (HCPCS codes: 45378, 45380, 45383, 45384, 45385, or G0121; and ICD-9 codes: V76.51 or 211.3). The sample sizes for the less restrictive cohorts were 22,044 and 24,720 for commercial and Medicare, respectively. The sample sizes for the more restrictive cohorts were 8,133 and 5,858 for commercial and Medicare, respectively. Comparisons within the commercial and within the Medicare populations examined the percent of repeat screening colonoscopies using both the less restrictive and more restrictive repeat rate criteria.

\section{Results}

\section{Screening colonoscopy}

In the databases used, the total number of eligible screening colonoscopies performed in 2010 was 489,575 in the commercial population and 56,496 in the Medicare population. Data regarding costs associated with screening colonoscopy claims are summarized in Table 2 for the commercial population and Table 3 for the Medicare population. Among the procedure codes used for screening colonoscopies, the average allowed amount for commercial claims was about twice the amount allowed

Table 2 Analysis of screening colonoscopies, commercial population

\begin{tabular}{|c|c|c|c|c|c|}
\hline \multirow[b]{2}{*}{ Code } & \multirow{2}{*}{$\begin{array}{c}\text { Screening } \\
\text { colonoscopies, } \\
\% \mathrm{~N}=489,575\end{array}$} & \multicolumn{4}{|c|}{ Average per colonoscopy } \\
\hline & & $\begin{array}{c}\text { Allowed } \\
\$\end{array}$ & $\begin{array}{c}\text { Paid } \\
\$\end{array}$ & $\begin{array}{c}\text { Cost share } \\
\$\end{array}$ & $\begin{array}{c}\text { Coinsurance } \\
\%\end{array}$ \\
\hline All screening colonoscopies & 100 & 2,146 & 1,812 & 334 & 15.6 \\
\hline Colonoscopies with no modifiers & 88.4 & 2,096 & 1,780 & 316 & 15.1 \\
\hline 45378 & 31.9 & 1,769 & 1,546 & 222 & 12.6 \\
\hline 45380 & 24.4 & 2,309 & 1,935 & 374 & 16.2 \\
\hline 45383 & 1.6 & 2,568 & 2,127 & 440 & 17.2 \\
\hline 45384 & 5.8 & 2,419 & 2,018 & 400 & 16.6 \\
\hline 45385 & 19.8 & 2,332 & 1,945 & 386 & 16.6 \\
\hline G0121 & 4.8 & 1,664 & 1,454 & 210 & 12.6 \\
\hline Colonoscopies with modifiers* 22, 52, 53, 73, and 74 & 0.4 & 1,911 & 1,650 & 260 & 13.6 \\
\hline Colonoscopies with other modifiers & 11.2 & 2,548 & 2,071 & 477 & 18.7 \\
\hline
\end{tabular}

* 22 = Service provided is greater than that usually required for the listed procedure.

$52=$ A service or procedure is partially reduced at the physician's discretion.

$53=$ Termination of a surgical or diagnostic procedure due to extenuating circumstances or those that threaten the well-being of the patient.

73 = Discontinued outpatient hospital/ambulatory surgery center procedure prior to the administration of anesthesia.

74 = Discontinued outpatient hospital/ambulatory surgery center procedure after administration of anesthesia. 
Table 3 Analysis of screening colonoscopies, medicare population

\begin{tabular}{|c|c|c|c|c|c|}
\hline \multirow{3}{*}{ Code } & \multirow{3}{*}{$\begin{array}{c}\text { Screening } \\
\text { colonoscopies, } \\
\% \mathrm{~N}=56,496\end{array}$} & \multicolumn{4}{|c|}{ Average per colonoscopy } \\
\hline & & Allowed & Paid & Cost share & Coinsurance \\
\hline & & $\$$ & $\$$ & $\$$ & $\%$ \\
\hline All screening colonoscopies & 100 & 1,071 & 795 & 275 & 25.7 \\
\hline Colonoscopies with no modifiers & 86.3 & 1,073 & 795 & 278 & 25.9 \\
\hline 45378 & 4.8 & 836 & 606 & 229 & 27.5 \\
\hline 45380 & 22.5 & 1,057 & 784 & 272 & 25.8 \\
\hline 45383 & 2.6 & 1,240 & 917 & 323 & 26.1 \\
\hline 45384 & 8.2 & 1,139 & 834 & 305 & 26.8 \\
\hline 45385 & 35.7 & 1,196 & 889 & 307 & 25.7 \\
\hline G0121 & 12.4 & 762 & 564 & 198 & 26.0 \\
\hline Colonoscopies with modifiers & & & & & \\
\hline $22,52,53,73$, and $74^{*}$ & 0.8 & 849 & 623 & 225 & 26.6 \\
\hline Colonoscopies with other modifiers & 13.0 & 1,067 & 808 & 258 & 24.2 \\
\hline
\end{tabular}

* 22 = Service provided is greater than that usually required for the listed procedure.

52 A service or procedure is partially reduced at the physician's discretion.

$53=$ Termination of a surgical or diagnostic procedure due to extenuating circumstances or those that threaten the well-being of the patient.

$73=$ Discontinued outpatient hospital/ambulatory surgery center procedure prior to the administration of anesthesia.

74 = Discontinued outpatient hospital/ambulatory surgery center procedure after administration of anesthesia.

for Medicare claims ( $\$ 2,146$ vs $\$ 1,071)$. Average beneficiary cost sharing for screening colonoscopy was $15.6 \%$ in the commercial population and $25.7 \%$ in the Medicare population. Compared with the commercial population, the portion of claims in the Medicare population with a colonoscopy that included a code for biopsy or polyp removal was about $25 \%$ higher (51.6\% vs $69.0 \%$ ). The majority of claims $(>85 \%)$ in the commercial and Medicare populations had no modifier codes and less than $1 \%$ of claims were associated with codes for discontinuation (53, 73, and 74) or the need to spend additional time cleaning the colon (22 and 52).

Over half of the people obtaining colonoscopies in the commercial analysis $(56.6 \%)$ had a claim for a prescription bowel preparation within 30 days prior to the procedure. Approximately 100 different National Drug Codes were identified for products that could be for bowel preparation and nearly $60 \%$ of all bowel preparation claims were for a branded product. Six bowel preparation products accounted for approximately $75 \%$ of the total number of prescriptions; this included 3 branded and 3 generic products (Table 4). The average cost sharing for branded products was $\$ 29.62$ and that of generic products was $\$ 8.31$. The allowed or paid cost associated with bowel preparation products was under $1 \%$ of the average allowed or paid cost, respectively, of the colonoscopy in the commercial population.

Approximately $43 \%$ of screening colonoscopies in the commercial population did not have a claim for a prescription bowel preparation within 30 days prior to the procedure. Although patients may have filled the prescription earlier than the 30 -day prior range examined, it

Table 4 Common bowel preparation prescriptions filled within $\mathbf{3 0}$ days prior to screening colonoscopy, commercial population

\begin{tabular}{|c|c|c|c|c|c|}
\hline \multirow[b]{2}{*}{$\begin{array}{l}\text { National } \\
\text { Drug Code }\end{array}$} & \multirow[b]{2}{*}{ Product name } & \multirow[b]{2}{*}{$\begin{array}{c}\text { Bowel preparation } \\
\text { prescriptions, } \\
\% \mathrm{~N}=208,178\end{array}$} & \multicolumn{3}{|c|}{ Average per prescription } \\
\hline & & & $\begin{array}{c}\text { Allowed } \\
\$\end{array}$ & $\begin{array}{c}\text { Paid } \\
\$\end{array}$ & $\begin{array}{c}\text { Cost share } \\
\$\end{array}$ \\
\hline Branded & & 42.1 & 16.83 & 8.52 & 8.31 \\
\hline 65649020175 & Moviprep ${ }^{\circledast}$ & 27.9 & 48.89 & 17.38 & 31.52 \\
\hline 52268052101 & Halflytely ${ }^{\circledR}$ Bowel Preparation Kit & 14.2 & 53.72 & 26.53 & 27.19 \\
\hline 65649070141 & Osmoprep ${ }^{\circledast}$ & 6.0 & 66.40 & 31.65 & 34.76 \\
\hline Generic & & 57.7 & 50.50 & 20.88 & 29.62 \\
\hline 10572040001 & PEG-3350/NaCl/Na Bicarbonate & 15.0 & 18.32 & 9.69 & 8.63 \\
\hline 62175044601 & PEG-3350/Electrolytes & 6.1 & 10.43 & 3.00 & 7.43 \\
\hline 68220013104 & Trilyte & 6.0 & 20.01 & 10.81 & 9.20 \\
\hline
\end{tabular}




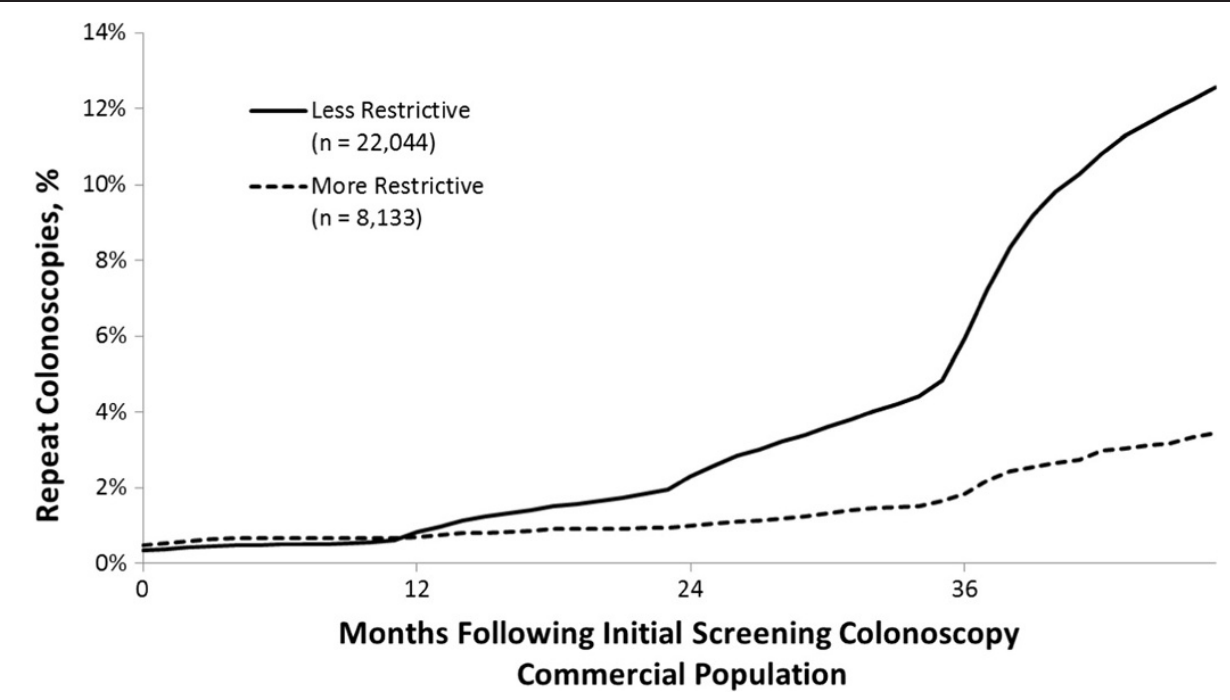

Figure 1 Cumulative colonoscopies repeated within 48 months following initial screening colonoscopy in the commercial population.

appears as though there is significant use of over-thecounter bowel cleansing products that are paid by the patient. Popular over-the-counter products general cost less than $\$ 25$.

\section{Repeat screening colonoscopy}

Using the less restrictive repeat rate criteria, the portion of patients obtaining a repeat screening colonoscopy within 4 years of the initial screening was $12.6 \%$ and $19.8 \%$ for the commercial $(\mathrm{n}=22,044)$ and Medicare ( $n=24,720)$ cohorts, respectively. Using the more restrictive repeat rate criteria, the percentage of repeat screening colonoscopies within 4 years of the initial screening colonoscopy was $3.5 \%$ and $3.8 \%$ for the commercial $(\mathrm{n}=8,133)$ and Medicare $(\mathrm{n}=5,858)$ cohorts, respectively. See Figures 1 and 2 .

\section{Discussion}

Treating CRC is expensive; based on Medicare data from 2008 and 2009 we found the average cost is estimated at $\$ 43,000$ within the first 12 months after diagnosis, not including prescription drug expense. Analysis of the MarketScan and Medicare 5\% beneficiary sample claims databases indicated that the average allowed cost in 2010 for screening colonoscopy was $\$ 2,146$ for commercial payers and $\$ 1,071$ for Medicare patients. Colonoscopy has been established as a cost-effective screening technique because it reduces mortality at relatively low incremental costs on a population basis [18].

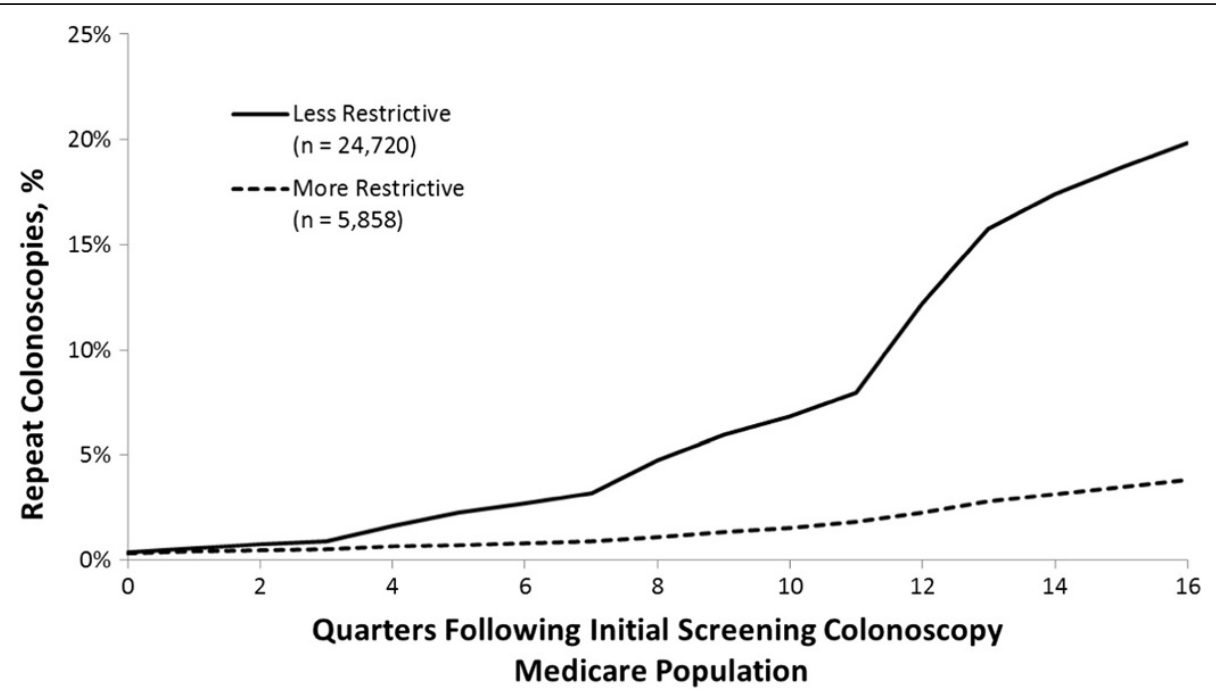

Figure 2 Cumulative colonoscopies repeated within 16 quarters following initial screening colonoscopy in the Medicare population. 
Our analysis revealed that more than $40 \%$ of colonoscopies did not have a claim for a prescription bowel preparation within 30 days prior to the procedure, suggesting the use of over-the-counter products in many patients.

Research indicates that approximately 1 in 4 to 1 in 6 patients are inadequately cleansed in preparation for colonoscopy [15-17]. Guidelines from the American Cancer Society and US Multi-Society Task Force on Colorectal Cancer recommend repeating the screening colonoscopy before planning a long-term surveillance program if the colon is not adequately prepared [19]. Given the high percentage of patients with inadequate preparation, the rate of repeat colonoscopy was anticipated to be higher than what was found in the commercial and Medicare populations. With suboptimal preparation, some clinicians may opt to recommend a shorter follow-up interval rather than repeat the colonoscopy [20], although our 4 year follow-up may include repeat colonoscopies as well as some with a shorter follow-up interval. The recent American College of Physician's clinical guidance on colorectal cancer screening notes concern with overuse of colonoscopy as well as under-use, and the source databases are expected to include both [21]. The low rate of repeats found in our data is of concern as research indicates miss rate of adenomas secondary to inadequate bowel preparation is significant. Lebwohl reports $43 \%$ of adenomas were missed among asymptomatic patients undergoing repeat colonoscopy [16]; Chokshi reports 34\% missed adenomas among average risk patients undergoing repeat colonoscopies, where repeats in both studies were due to inadequate preparation [13].

A limitation of this analysis is that the data did not capture the level of bowel preparation quality. In addition, the analysis relies on claims coding to make inferences, which can introduce biases such as caused by miscoding or under-coding. Also, the data from the analysis is based on historical numbers, and may not be appropriate for any one particular organization given the variability in health care benefits. However, the use of claims databases to identify individuals who have had screening colonoscopy seems supported by a recent comparison of medical records and claims [22].

Tabulating repeat rates only for lives having four years of continuous enrollment allowed for complete followup for all initial colonoscopies, but it could have introduced biases. For the commercial population, breaks in enrollment in the source database are typically due to shifts in employment or changing coverage such as obtaining Medicare coverage through aging or disability. Such individuals would have been excluded, and such individuals could be less healthy than those with continuous enrollment. For the Medicare population, breaks in enrollment are typically due to entry into Medicare Advantage or death. The impact of the continuous enrollment criteria on the results is unclear.

\section{Conclusions}

The average allowed cost in 2010 for screening colonoscopy was $\$ 2,146$ for commercial payers and $\$ 1,071$ for Medicare patients. Given the reportedly high rates of patients with inadequate preparation for colonoscopy, the rate of repeat colonoscopy was anticipated to be higher than what was found in the commercial and Medicare populations. This is of risk concern because of significant miss rates of adenomas secondary to inadequate bowel preparation.

\section{Abbreviations \\ CRC: Colorectal cancer; HCPCS: Healthcare Common Procedure Coding System; ICD-9: International Classification of Disease.}

\section{Competing interests}

Financial support: Financial support for the analysis was provided by Ferring Pharmaceuticals Inc. The authors were not compensated for their work on this manuscript. Professional medical writing assistance was supported by Ferring Pharmaceuticals Inc.

Potential competing interests: The authors have no competing interest to declare.

\section{Authors' contributions}

$\mathrm{CS}, \mathrm{BP}$, and JP contributed to the study design, data analyses, and ensuing report of study results. BP, CS and JP helped to edit the manuscript. All authors read and approved the final manuscript.

\section{Acknowledgments}

The authors take full responsibility for the content of this manuscript. The authors acknowledge The JB Ashtin Group, Inc. who provided some assistance in preparing this manuscript for publication based on the authors' analysis and direction.

Received: 12 July 2013 Accepted: 31 January 2014

Published: 26 February 2014

References

1. Siegel R, Naishadham D, Jemal A: Cancer statistics, 2012. CA Cancer J Clin 2012, 62:10-29.

2. Matsui T, Yao T, Iwashita A: Natural history of early colorectal cancer. World J Surg 2000, 24:1022-1028.

3. Levin B, Lieberman DA, McFarland B, Smith RA, Brooks D, Andrews KS, Dash C, Giardiello FM, Glick S, Levin TR, Pickhardt P, Rex DK, Thorson A, Winawer SJ, American Cancer Society Colorectal Cancer Advisory Group; US Multi-Society Task Force; American College of Radiology Colon Cancer Committee: Screening and surveillance for the early detection of colorectal cancer and adenomatous polyps, 2008: a joint guideline from the American Cancer Society, the US Multi-Society Task Force on Colorectal Cancer, and the American College of Radiology. CA Cancer J Clin 2008, 58:130-160.

4. Rex DK, Johnson DA, Anderson JC, Schoenfeld PS, Burke CA, Inadomi JM, American College of Gastroenterology: American College of Gastroenterology guidelines for colorectal cancer screening 2009. Am J Gastroenterol 2009, 104:739-750.

5. US Preventive Services Task Force: Screening for colorectal cancer: U.S. Preventive Services Task Force recommendation statement. Ann Intern Med 2008, 149:627-637.

6. Benson AB 3rd, Arnoletti JP, Bekaii-Saab T, Chan E, Chen YJ, Choti MA Cooper HS, Dilawari RA, Engstrom PF, Enzinger PC, Fleshman JW Jr, Fuchs CS, Grem JL, Knol JA, Leong LA, Lin E, May KS, Mulcahy MF, Murphy K, Rohren E, Ryan DP, Saltz L, Sharma S, Shibata D, Skibber JM, Small W Jr, 
Sofocleous CT, Venook AP, Willett C, National Comprehensive Cancer Network: Colon cancer. J Natl Compr Canc Netw 2011, 9:1238-1290.

7. Zauber AG, Lansdorp-Vogelaar I, Knudsen AB, Wilschut J, van Ballegooijen $M$, Kuntz KM: Evaluating test strategies for colorectal cancer screening: a decision analysis for the U.S. Preventive Services Task Force. Ann Intern Med 2008, 149:659-669.

8. Kahi CJ, Imperiale TF, Juliar BE, Rex DK: Effect of screening colonoscopy on colorectal cancer incidence and mortality. Clin Gastroenterol Hepatol 2009, 7:770-775.

9. Zauber AG, Winawer SJ, O'Brien MJ, Lansdorp-Vogelaar I, van Ballegooijen M, Hankey BF, Shi W, Bond JH, Schapiro M, Panish JF, Stewart ET, Waye JD: Colonoscopic polypectomy and long-term prevention of colorectalcancer deaths. N Engl I Med 2012, 366:687-696.

10. Centers for Disease Control and Prevention (CDC): Cancer screening United States, 2010. MMWR Morb Mortal Wkly Rep 2012, 61:41-45.

11. American Cancer Society: Colorectal Cancer Facts \& Figures 2011-2013. Atlanta: American Cancer Society; 2011.

12. Department of Health and Human Services: Healthy people 2020 objectives. http://www.healthypeople.gov/2020/topicsobjectives2020/ default.aspx

13. Chokshi RV, Hovis CE, Hollander T, Early DS, Wang JS: Prevalence of missed adenomas in patients with inadequate bowel preparation on screening colonoscopy. Gastrointest Endosc 2012, 75:1197-1203.

14. Rex DK, Imperiale TF, Latinovich DR: Impact of bowel preparation on efficiency and cost of colonoscopy. Am J Gastroenterol 2002. 97:1696-1700

15. Harewood GC, Sharma VK, de Garmo P: Impact of colonoscopy preparation quality on detection of suspected colonic neoplasia. Gastrointest Endosc 2003, 58:76-79.

16. Lebwohl B, Kastrinos F, Glick M, Rosenbaum AJ, Wang T, Neugut Al: The impact of suboptimal bowel preparation on adenoma miss rates and the factors associated with early repeat colonoscopy. Gastrointest Endosc 2011, 73:1207-1214

17. Hendry PO, Jenkins JT, Diament RH: The impact of poor bowel preparation on colonoscopy: a prospective single centre study of 10,571 colonoscopies. Colorectal Dis 2007, 9:745-748.

18. Sonnenberg A, Delco F, Inadomi JM: Cost-effectiveness of colonoscopy in screening for colorectal cancer. Ann Intern Med 2000, 133:573-584.

19. Winawer SJ, Zauber AG, Fletcher RH, Stillman JS, O'Brien MJ, Levin B, Smith RA, Lieberman DA, Burt RW, Levin TR, Bond JH, Brooks D, Byers T, Hyman N, Kirk L, Thorson A, Simmang C, Johnson D, Rex DK, US Multi-Society Task Force on Colorectal Cancer; American Cancer Society: Guidelines for colonoscopy surveillance after polypectomy: a consensus update by the US Multi-Society Task Force on Colorectal Cancer and the American Cancer Society. Gastroenterology 2006, 130:1872-1885.

20. Larsen M, Hills $\mathrm{N}$, Terdiman J: The impact of the quality of colon preparation on follow-up colonoscopy recommendations. Am J Gastroenterol 2011, 106:2058-2062.

21. Qaseem A, Denberg TD, Hopkins RH, Humphrey LL, Levine J, Sweet DE, Shekelle P: Screening for colorectal cancer: a guidance statement from the American College of Physicians. Ann Intern Med 2012, 156(5):378-386.

22. Gupta S, Tong L, Anderson P, Rose B, Carter E, Koch M, Argenbright K, Ahn C, Allison J, Skinner CS: Measurement of colorectal cancer test use with medical claims data in a safety-net health system. Am J Med Sci 2013, 345(2):99-103.

\section{doi:10.1186/1472-6963-14-92}

Cite this article as: Pyenson et al:: Costs and repeat rates associated with colonoscopy observed in medical claims for commercial and Medicare populations. BMC Health Services Research 2014 14:92.

\section{Submit your next manuscript to BioMed Central and take full advantage of:}

- Convenient online submission

- Thorough peer review

- No space constraints or color figure charges

- Immediate publication on acceptance

- Inclusion in PubMed, CAS, Scopus and Google Scholar

- Research which is freely available for redistribution

Submit your manuscript at www.biomedcentral.com/submit
Biomed Central 